\title{
Integrating land use and transport knowledge in strategy-making
}

\author{
Marco Te Brömmelstroet · Luca Bertolini
}

Published online: 25 July 2009

(C) The Author(s) 2009. This article is published with open access at Springerlink.com

\begin{abstract}
There is broad and growing consensus regarding the central place of integrated Land Use and Transport (LUT) strategy development in establishing more efficient and sustainable urban environments. However, empirical evidence shows that such integration is hard to achieve in daily planning practice, due to many institutional barriers and substantive differences. More specifically, the tools developed to support LUT strategy development have very low implementation rates in daily planning practice. This paper introduces the concept of 'knowledge generation' as a potentially useful mechanism for closing the gap between support tools and planning practice. Through two specific Dutch planning cases, we analyze the applicability of this concept in supporting integrated LUT strategy development. The paper focuses on the developed strategies, how these differ from current practice, and how knowledge generation supported their development. We argue that socialization produces shared strategies and that effective socialization needs to be supported by efficient mutual exchange between tacit and explicit knowledge. We conclude by discussing the implications of this argument for the wider practice of LUT planning integration.
\end{abstract}

Keywords Land use and transport planning · Planning support systems . Strategy making $\cdot$ Knowledge generation

\author{
Abbreviations \\ LUT Land use and transport \\ PSS Planning support systems
}

M. Te Brömmelstroet $(\bowtie) \cdot$ L. Bertolini

Amsterdam Institute for Metropolitan and International Development Studies (AMIDSt), University of Amsterdam, Nieuwe Prinsengracht 130, 1018 VZ Amsterdam, The Netherlands e-mail: marco@transport-planning.eu

L. Bertolini

e-mail: 1.bertolini@uva.nl 


\section{The struggle for land use and transport integration}

As extensively discussed by other scholars, there is a growing awareness that the integration of land use and transport (LUT) planning is a crucial prerequisite for more sustainable planning outcomes (see for example Banister 2002, 2005; Cervero 1998; Meyer and Miller 2001; TRB 2004). However, in the Netherlands (and in other countries) such integration is scarcely present in daily planning practice (see for instance Hull and Tricker 2006). If anything, one can speak of policy coordination rather than 'integration'; i.e., it is dialogue or information exchange which is geared at avoiding conflicts between projects, but does not seek to establish similar policy goals (Stead et al. 2004). Achieving integration in earlier phases of planning (for example strategy development, goal orientation or visioning) can potentially produce shared policy goals, which would promote mutually reinforcing (instead of obstructing) land use and transport measures.

A wide variety of barriers block such early integration, for example: distinctive budgets, different procedures, weak/contradictory incentives for cooperation, reluctant departmental culture or the lack of efficient management mechanisms (see Cabinet Office 2000; Hull and Tricker 2006; TRB 2004). Beside these institutional barriers there are large substantive differences between the domains of land use and transport planning in: planning objects (places vs. networks/flows); tools and instruments (e.g., spatial GIS vs. mathematical transport models); operational modes (holistic visioning vs. optimizing problem solving); and educational carriers. Hence, the two professions speak different professional languages (a point further elaborated in Te Brömmelstroet and Bertolini 2008; see also van der Bijl and Witsen 2000; Wachs 1985). In early planning phases, focusing on the development of new (and shared) knowledge and group learning, this lack of a common lexicon is particularly problematic (Couclelis 2005; Jones and Lucas 2005; Klosterman 2007). Tennøy recently used the concept of conflicting reference frames (Schön and Rein 1994) to analyze the conflicting ways that different parties (e.g., land use and transport planners) view the issue of sustainability (Tennøy 2009). This showed how this results in two different sets of planning languages, which are hard to integrate. Although we recognize the great importance of institutional barriers to LUT integration, in this paper we focus on these substantive barriers, while they have been addressed much less extensively in the literature.

Many (computer based) tools and instruments have been developed to try and provide such a common LUT language for integrated visioning or strategy development, for example UrbanSim (Waddell 2002) and MARS (Emberger et al. 2006) (for extensive overviews see Wegener 2005; Wilson 1998). However, these instruments face serious implementation problems. Recent research shows that the gap between instrument development (by consultants and/or universities) and daily planning practice creates the main implementation bottlenecks. The present technology-rather than user-focus produces unsuitable instruments: focused only on scientific rigor rather than also on practical relevance; not adapted to the complex and dynamic planning context; not transparent; not user friendly and inflexible. Therefore, such instruments cannot link-up with the context specifics of early LUT integration (Te Brömmelstroet 2009). These findings mirror the wider academic debate on implementation bottlenecks of these so-called Planning Support Systems (PSS) (see for example Geertman 2006; Uran and Janssen 2003; Vonk et al. 2005) and on the role of transportation models in an increasingly communicative planning practice (see e.g., Timms 2008; Willson 2001). 
Towards improved support

Similar problems are addressed in the knowledge management literature. In recognition of the limited role of scientific and technical information in decision-making, it introduced concepts which addressed the personal and softer dimension of knowledge. In their seminal study on innovations in Japanese companies, Nonaka and Takeuchi (1995) introduced the concept of knowledge generation. Innovating companies designed enabling environments in order to provide a confrontation between technical information and the personal dimensions of knowledge. Iteratively going through these confrontations produced new knowledge and thus innovative potential. This provides useful insights for successfully linking the technical information of LUT PSS with personal knowledge.

To assess this potential, we have used the concept of knowledge generation to structure two exploratory cases where a group of planners engaged in integrated LUT strategymaking in the Netherlands on a regional (Amsterdam) and local scale (Breda). This paper will (1) describe these applications, focusing on their divergence from existing practices, and (2) analyze the contributions of the knowledge generation concept.

Our research methodology followed the logic of realistic evaluation (Pawson and Tilley 1997), which seeks to identify a solution for a particular class of problems, or a 'technological rule'. A technological rule follows the general form: "if you have a context $\mathrm{C}$, use an intervention type I, to achieve outcome O through the mechanisms M" (Denyer et al. 2008; Pawson and Tilley 1997). In Sect. 2 of the paper, we will introduce a division of knowledge and elaborate on the concept of knowledge generation, exploring its possible applicability to LUT strategy-making. Sections 3 and 4 will provide detailed examinations of the two cases, including: the context (LUT planners in LUT strategy design processes on the local/regional scale in the Netherlands), the intervention (the concept of knowledge generation) and the outcome (integrated strategies). The fifth section will further analyze the general relationship between the identified mechanisms and outcomes, after which the paper will close with conclusions and a discussion of possible implications for wider planning practice and support.

\section{Knowledge, knowledge generation and planning support}

The differences in knowledge used in LUT planning are a substantive barrier which hinders integrated LUT strategy-making. The academic domain of knowledge management offers useful insights for overcoming the gap between these professional languages.

\section{Explicit and tacit knowledge}

In the field of knowledge management, Polanyi (1967) introduced the distinction between explicit and tacit knowledge. Explicit types of knowledge are formal (ex. data, scientific formulas and general/universal principles and theories) and are therefore easily codified with a wide validity. Explicit knowledge usually resides within certain (planning) disciplines, following institutionalized rules about: the manner of creating new knowledge, conducting analysis or surveys, and the validity of evidence or argumentation. Recently, Healey used the term systematized to refer to similar knowledge in strategy-making processes (Healey 2007). The second dimension is tacit knowledge, sometimes referred to as invisible knowledge. This is personal and hard to formalize, which makes it difficult to communicate or share with others (for example practical know-how, intuitions and 
hunches). In the words of Polanyi: "one can know more than one can tell" (1967, p. 138). Tacit knowledge and information are not necessarily related to particular disciplines, but rather to people's (ex. planners) individual experiences (Gibbons et al. 1994). Nonaka and Konno (1998, p. 42) asserted that, "tacit knowledge is deeply rooted in an individual's actions and experience as well as in the ideas, values, or emotions he or she embraces". Polanyi introduced the concept of tacit knowledge to conceptualize the knowledge that (by definition) cannot be described or talked about (writing it down would make it explicit). Here, we will use the term less strictly to broadly conceptualize the experiential knowledge of planners in order to assess its relationship with the explicit (or systematized) knowledge of for instance transport models (an argument also made by Healey 2007).

Several authors (Gibbons et al. 1994; Innes 1998; Khakee et al. 2000; Scharmer and Kaufer 2000) emphasized that tacit knowledge plays an increasingly important role in formal decision-making, and should be duly recognized in planning processes. If planners want to address complex socio-economic planning problems (and thus cope with the many associated uncertainties), explicit knowledge and information should play an important role; however, it is pivotal to realise that the explicit should be combined and confronted with the tacit. If explicit information is not made understandable and more transparent, and if it remains disconnected from daily practice, the practitioners will not use it. In addition to satisfying academic rigour, scientific knowledge should thus also be relevant, useful and understandable for the planning actors. This was already one of the key elements of Friedmann's transactive planning (Friedmann 1973). Interestingly, instead of highlighting the 'democratic' motives for improving inclusiveness, "the argument for transactive planning is that expert knowledge should be wedded to experiential knowledge to achieve a greater rationality in decision-making" (ibid., p. 378).

\section{Knowledge generation}

At the end of the last century, Western and Japanese research on knowledge management arrived at similar insights concerning knowledge generation, describing it as a social process. Creating rigorous and relevant knowledge required linking the explicit with the tacit through interaction (Gibbons et al. 1994; Nowotny et al. 2001). In their seminal work on knowledge creation in Japanese companies, Nonaka and Takeuchi (1995, pp. 61-71) conceptualized four key modes of knowledge conversion in their SECI model (Nonaka and Takeuchi 1995, pp. 61-71):

- Socialization (tacit with tacit): sharing experiences to create new tacit knowledge, observing other participants, brainstorming without criticism;

- Externalization (tacit with explicit): articulating tacit knowledge explicitly, writing it down, creating metaphors, indicators and models;

- Combination (explicit with explicit): manipulating explicit knowledge by sorting, adding, combining, looking to best practices; and.

- Internalization (explicit with tacit): learning by doing, developing shared mental models, goal based training.

Figure 1 shows the resulting matrix of knowledge generation. The spiral represents a process of knowledge generation within a group, iteratively acting in all four modes of knowledge conversion.

Various authors criticized the model due to its methodological inconsistency (tacit knowledge per definition cannot be made explicit) (Tsoukas 2003) and the limited empirical support for the model (Gourlay 2006). In spite of these shortcomings (also 
Fig. 1 The SECI model of knowledge generation (adapted from Nonaka and Takeuchi 1995, p. 61)

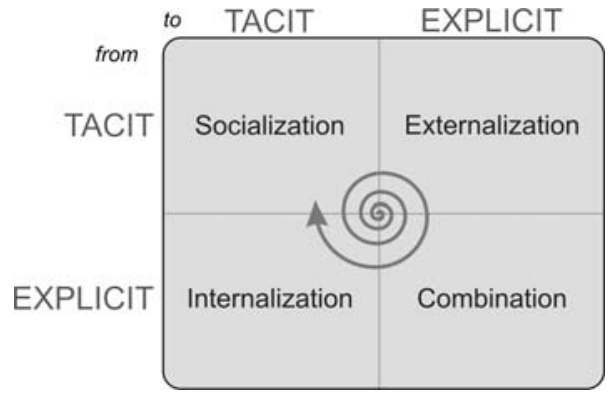

recognized by Nonaka et al. (2006), the SECI model has enjoyed enthusiastic acceptance in organizational science and practice, and also has a paradigmatic status in the field of knowledge management. We use it to provide a conceptual framework for linking different kinds of explicit scientific knowledge with strategic urban planning processes.

\section{Knowledge management to support strategy-making}

Land Use and Transport strategy-making is a social learning process in which actors use not only explicit information but also earlier experiences, concepts from their educational careers and personal feelings (Healey 2007; Mintzberg and Waters 1985; Simon 1993). The concept of knowledge generation can be a useful guiding principle for improving this learning process in integrated LUT strategy-making. In this, it links to, and attempts to further articulate the concept of the reflective practitioner, as originally developed by Donald Schön (1983).

By experiencing the four knowledge conversion modes, planners can develop a shared explicit language and use it to develop integrated strategies. Socialization provides a platform where people can interact and learn from each others' concepts of reality, views of the planning object, working modes and professional languages. In this first important step, the participants build a common understanding of each others' tacit foundations. In step two, Externalization, the planners are challenged to formalize this in a shared working process (including a planning problem, planning steps and a preferred outcome) and in a shared set of indicators, information and models. Externalization takes place in dialogue with PSS developers who can explain the available explicit LUT knowledge and its possibilities/shortcomings. The end result is a contextualized professional LUT language, combining the planners' preferences and the available PSS. In the third knowledge conversion step, Combination, the PSS developers link different models and indicators (based on a mutual LUT language) which provide support for the different steps of the externalized strategy-making process (ex. designing or choosing alternatives). Internalization occurs when the PSS output is presented to the planners (ex. demonstrating the effects of alternative strategies). In order for this explicit LUT knowledge to be useful for the planners, it has to be explained and discussed. The PSS developers have to provide transparency by explaining the assumptions and uncertainties in the modelling, thus enabling the planners to internalize these results and to discern their cause-effect relationship. After these four steps, the planners have a mutually understandable and applicable set of explicit knowledge. Through the use of this language, some of their tacit knowledge has changed (land use planners incorporate new transport insights and vice versa), thus adding value to other strategy-making processes. Also, new shared LUT 
strategies have been developed. After the four steps are finished a new round can start, when the planners use the internalized knowledge to discuss new interventions.

This knowledge management approach to planning support shares elements of other normative methods that aim to support the use of explicit knowledge in collaborative working. Joint Fact Finding aims to facilitate the use of technical or scientific knowledge in a contested environment (Ehrmann and Stinson 1999, p. 2). However, its focus is to fill information gaps and explore uncertainties and does not explicitly give guidelines for the use of this information and the iterative (and reciprocal) exchange with the tacit knowledge of participants. Group Model Building facilitates the development of a shared view on reality, often a conceptual framework of a problem (Vennix 1996). This important first step in many collaborative endeavours does still not mention how to organize the full circle of knowledge generation. The SECI model emphasizes - in addition to these methods - the importance of going through at least one full circle of tacit-explicit-tacit. It identifies four specific phases of knowledge transition with unique dynamics and thereby adds to our understanding of how such processes work and can work.

To explore if and how the SECI model can support real-life integrated LUT strategymaking processes, we applied it in two Dutch cases: in the Amsterdam region and in the city of Breda. In both cases, planners from the municipality approached the University of Amsterdam to guide them in a process of integrated land use-transport strategy making. Together with these planners, potentially relevant providers of explicit planning support knowledge were selected and asked to support this process. The authors of this article were involved in both cases as organizers and chairs of the sessions. Both experiences were made possible by the Dutch national government sponsored research programme TRANSUMO ("Transition to Sustainable Mobility"). While addressing real-world issues with real-world stakeholders, they had no formal relationship with the political decisionmaking process.

From a methodological point of view, we followed the realistic evaluation approach of (Pawson and Tilley 1997) as described above. Following this approach, below we will describe the context, intervention and outcome of both cases and how these differ from existing practices. Based on data obtained from direct observations, questionnaires and indepth interviews, we will then explore the link between the outcome and the concept of knowledge generation (the hypothesized mechanism).

\section{Facilitating growth in the amsterdam metropolitan area}

Context: substantive and institutional

The Amsterdam metropolitan area (Fig. 2) is facing substantial land use and transport challenges in the coming decades. As one of the few Dutch regions where economic and population growth is foreseen in all future scenarios, the region has to plan for a large number of new high quality jobs and houses (both around 150,000 until 2030). However, mainly due to nature preservation and airport noise regulations, space for new urban development is scarce. In addition, the region is facing dramatic growth in traffic flows and congestion in the near future. Instead of seeing these as separate challenges needing separate strategies, the municipal (and regional) land use and transport planners are looking for ways to develop integrated strategies.

Many of the planners (especially in Amsterdam) already work together in several (thematic or geographical) project teams. The Municipality of Amsterdam is also known 


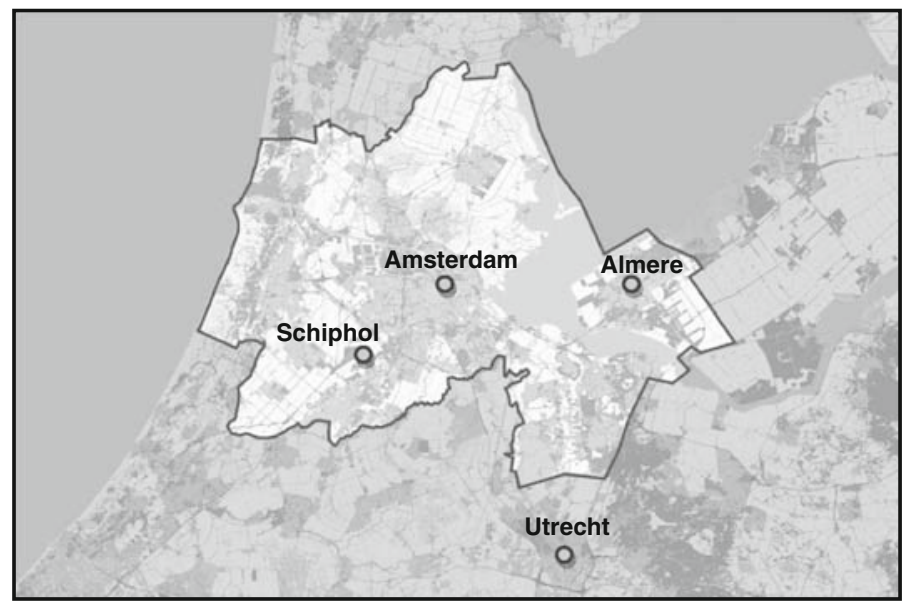

Fig. 2 The Amsterdam Metropolitan Area (adapted from Noordvleugel 2008)

for its strong strategic capacity and close collaboration with the university (Healey 2007). However, the planners experienced that it was sometimes difficult to develop strategies together. In this case, not so much due to separated institutions, but because of difficulties in using information that was understandable and meaningful in both planning domains.

Since the 1980s, Amsterdam has been using its own in-house transportation model (GenMod), a static and multimodal four-step transportation model based on household surveys and mobility counts. GenMod is capable of calculating transportation impacts for both land use and transport developments in the Amsterdam metropolitan area. Despite the fact that it is considered one of the best transportation models in the Netherlands, it is not being used to support strategic planning processes in early phases (let alone integrated land use and transport planning endeavours), but only to assess and detail already developed strategies. This is felt as a missed opportunity to develop more LUT integrated strategies.

Intervention: the sessions

In 2006 and 2007 six sessions were held in the Amsterdam region. In these sessions land use and transport planners from the Municipality of Amsterdam and the Amsterdam Metropolitan Area (Stadsregio Amsterdam), transport modellers and a strategic planner from the Dutch Railways set out to develop integrated LUT strategies for the region up to 2030. We used GenMod to support this effort. The sessions were designed to allow the different phases of the SECI model to take place (see Discussion under 'Mechanism' below).

In the first step, the participants discussed and agreed on the framing of the LUT planning problem - to foster economic growth up to 2030 (and thus create space for 150.000 additional jobs and houses) with supporting LUT strategies. The second step involved a discussion on how to shape the planning process for developing integrated strategies. The iterative strategy-making process chosen had three steps: first diverging (developing alternative urbanization and [later] transport interventions), then converging (assessing and comparing effects) and finally selecting (identifying strategies). The participants also agreed that they did not want to develop a 'final LUT plan', but rather wanted to develop common 
insights in 'no regret', or 'robust' strategies (strategies that can work in different future scenarios) and in LUT interdependencies ("if...then..." statements, improving understanding of he implications of the options available). In the third step, the PSS developers introduced information deemed useful for this planning process. The participants discussed it and consequently selected as pertinent: (for diverging strategies) spatial accessibility and sustainability maps based on cumulative opportunity measures and measured in travel time and distance; (for converging strategies) network maps of the effects of strategies on the road and transit networks; and a number of indicators for the effects of strategies (overall accessibility indicators for the region). By using it, the information was also transformed, namely made simpler and more transparent. In the fourth step, spanning three separate sessions, they developed shared LUT strategies. After two design sessions, the effects on the indicators of the developed strategies were presented. They supported the final step, the selection of 'no regret' strategies (using different sets of assumptions on future conditions in the region) and interdependencies ("if we do A...than we should be aware of effects as B"). All the steps are synthesized in Fig. 3 bellow:

Outcome: integrated LUT strategies

Through this process (extensively described in Te Brömmelstroet and Bertolini 2008), the group of participants developed a list of 'no regret' strategies and LUT interdependencies. These are specific outcomes of this group learning exercise and should be interpreted solely in this context. The following examples of 'no regret' LUT strategies highlight how they differ from current practices:

- Land use choices, due to their marginal influence on accessibility, can and should be based on existing accessibility characteristics (instead of trying to influence accessibility characteristics through land use choices). Land use planners reported gaining new insight that the influence of the existing regional urban fabric on the cumulative opportunity measures is very strong and minimizes the effects of new land use strategies.

Fig. 3 Intervention steps to support integrated LUT strategymaking

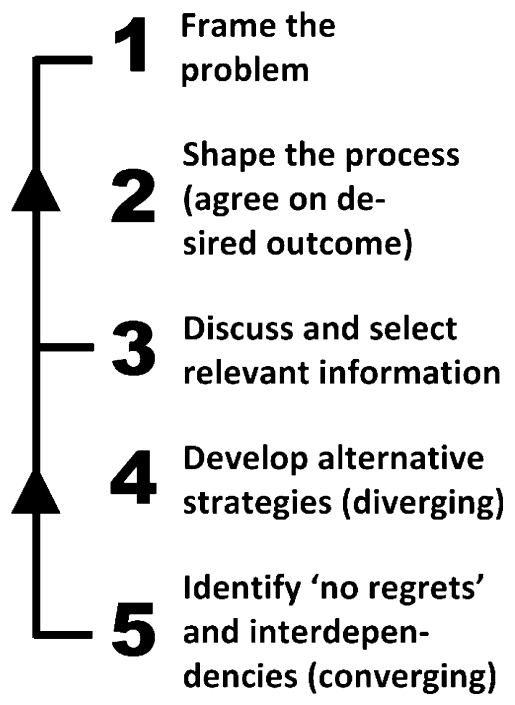


- A polycentric 'network city' (centred on multiple public transport nodes) is not less accessible or less sustainable than a 'compact city'. One of the alternative urbanization strategies based on this concept scored high (or even higher than the other alternatives) on sustainability indicators, which was a surprise for many of participants.

- Spatial programs should be developed in existing transit corridors. During the exercise it was discovered that some of the existing transit corridors offer additional opportunities for developing new station areas (notwithstanding existing restrictions such as nature reservation).

- The orbital bus rapid transit system should be extended to link several existing/ upcoming housing developments with working areas. This is not a new idea, but during the exercise it was more widely shared and supported with explicit information.

- Once the currently planned extensions are completed, development of the highway network should stop. This highly controversial idea was supported by the indicators which showed that by implementing demand related interventions (i.e., road pricing) the current road network will retain sufficient capacity, even with increases in houses and jobs.

- Transit travel speeds towards the new town of Almere and capacity towards the airport Schiphol should be increased. The planners learned that job accessibility for Almere was contingent on reducing the travel time to Amsterdam within acceptable limits (in addition to direct job creation in Almere). On the other hand, Schiphol is already close to other important locations (also in travel time), but the number of tracks will become a bottleneck in the (near) future.

Based on the strategy design process and the effects shown in maps and indicators, the participants identified three important LUT interdependencies:

- If more housing is developed in and around Almere, then it has to be on the west side and a direct and fast transit link to Amsterdam (south and central) is crucial.

- If there is development around transit stations, then especially working (rather than housing) functions can have a significant effect on the modal split. Based on their research, the Dutch Railway planner explained that people are more likely to commute by train if the transit nodes are close to their destination. There is a sufficient number of acceptable travel options to the station on the origin side (including own bike or car); however, opportunities are lacking on the destination side. Many of the participants had not explicitly recognized this issue before the sessions.

- If the housing targets in the western part of the region (Bollenstreek) cannot be met, then regional growth figures have to be reduced. One of the land use planners emphasized the crucial position of this area, a completely new notion for the other participants.

Overall, the outcomes were not entirely new to the planners. However, the participants did find the concepts more thought-out, jointly deliberated, and supported by relevant information. On the individual level, some planners gained more confidence and insight in the use of the supporting model. As a result participants stated that there is an increased chance that such similar integrated strategy development processes will be used in the Amsterdam metropolitan area in the future. The questionnaires revealed that most planners felt that they had a more constructive attitude towards the need and possibility of strategy integration, due to the focus on collectively accepted explicit knowledge. This made it possible to discuss land use impacts of — on first sight—irrelevant transport strategies and 
vice versa. Especially the platform provided by the accessibility maps seemed to allow a free, and yet structured flow of tacit knowledge.

Mechanism: knowledge generation

The organized sessions helped the LUT planners to develop integrated strategies. The participants considered that process as an improvement to existing practices, especially in its enhanced sharing of insights and its providing improved support for concepts. To illustrate the mechanism behind this improvement, below we will discuss the four components of the SECI spiral of knowledge generation and how these supported the development of integrated strategies.

\section{Socialization}

In the first step (see Fig. 3), defining a shared LUT planning problem, the planners had to link together the specific issues of their domain and arrive at a definition of the overarching shared problem-how to facilitate growth in the region. Also, during the first step of designing alternatives, they exchanged tacit knowledge; experience and personal knowledge about the area. In turn, they increased their understanding of its strengths/weaknesses and produced individual strategies for intervention.

In the second step, the participants discussed their view of current planning processes and how to improve them through integration. This resulted in a shared view on the reasons why it is difficult to develop an integrated LUT strategy in practice and how to organize a process bridging these difficulties. Although one land use planner stated that, "with the current area-based approach [...] there is already an integral way or working," another land use planner addressed that this open start, "without a presumption about which planning domain is leading," was a positive change compared to common practices.

Finally, socialization occurred when the participants identified and shared their viewpoints regarding 'no regret' strategies and LUT interdependencies (in the words of one transport planner, "especially the interactive way of working was positive").

\section{Externalization}

In the third step, participants translated their tacit into explicit knowledge, discussing different indicators suitable for the defined planning issue and thereby describing the issue in terms of explicit information. In the fourth step, designing scenarios, the planners externalized their strategies in concrete interventions on the map. This was a crucial trigger for dialogue between land use and transport planners; they had to explain to each other their preferred choices and the LUT strategy suitability of the particular choice.

\section{Combination}

Combination occurred when the planners used several different forms of model outputs to assess the effects of specific planning interventions in the fourth and fifth steps. The planners preferred having a large number of impact maps at their disposal, categorized in a digital environment. Such a system enabled them to access and combine several maps and indicators, thus articulating complex trends in multiple comprehensible maps. 


\section{Internalization}

The participation of the modellers during all of the steps was crucial for internalization; they formed the essential bridge between the explicit information of GenMod and the tacit knowledge of the planners. In the last two steps, where the effects of certain interventions were presented, the planners asked the modellers many questions about the assumptions behind the information and the meaning of the presented indicators. Through dialogue, they could use the information to first optimize their own strategies and later to develop shared strategies. One transport planner emphasized the importance of making the indicators useful by providing "good explanation and clarification". Simple (understandable) explicit information provided a necessary platform for exchanging tacit information. At first the modellers provided information (distance decay, competition and congestion effects) that was too complicated to be internalized and used, but through dialogue the information and its understanding were improved.

Due to this well supported internalization, the planners could start a second knowledge generation cycle aimed at further strategy development. The participants' questionnaire responses highlighted the value of socialization, for example: "as a land use planner, I am now more aware of the different ways of using accessibility measures than before" and "although the information is often not exactly what you want, you are more aware of the information that is used."

\section{Integrating station development and land use plans in Breda}

Context: substantive and institutional

The city of Breda aims to develop a peripheral railway station on an existing railway line, located between its urban centre and the neighbouring city of Tilburg. The station should function as a Park and Ride facility (located near the A27 highway) and it should create opportunities for more public transport oriented development in the future (see top of Fig. 4). This idea fits in the regional perspective of an intensified regional railway network (Brabantstad 2003). Parallel to this transport concept, Breda developed a strategic land use plan for the eastern part of the city as an extension of the existing urban fabric, illustrated in Fig. 3. The distance between the proposed railway station and the leisure centre (projecting 2 million visitors a year) is about one-and-a-half kilometres. The distance to the new housing and working areas is over three kilometres (while the A58 highway is only $500 \mathrm{~m}$ away!). This evidently disjointed land use and transport thinking inspired a group of planners to approach us to explore the scope for an improved integrated strategy for this area.

As a baseline, this group of planners was less used to work across disciplinary boundaries than the Amsterdam group. In interviews prior to the sessions, the planners stated that overall there is limited cooperation between the land use and transport planning domain and that, in contrast to Amsterdam, they have very limited in-house modelling capacity (relying instead on input from consultancy firms hired for specific projects).

Intervention: the sessions

In Breda, four sessions were facilitated in the period between April and November 2007. Land use and transport planners from the municipality of Breda and the neighbouring 


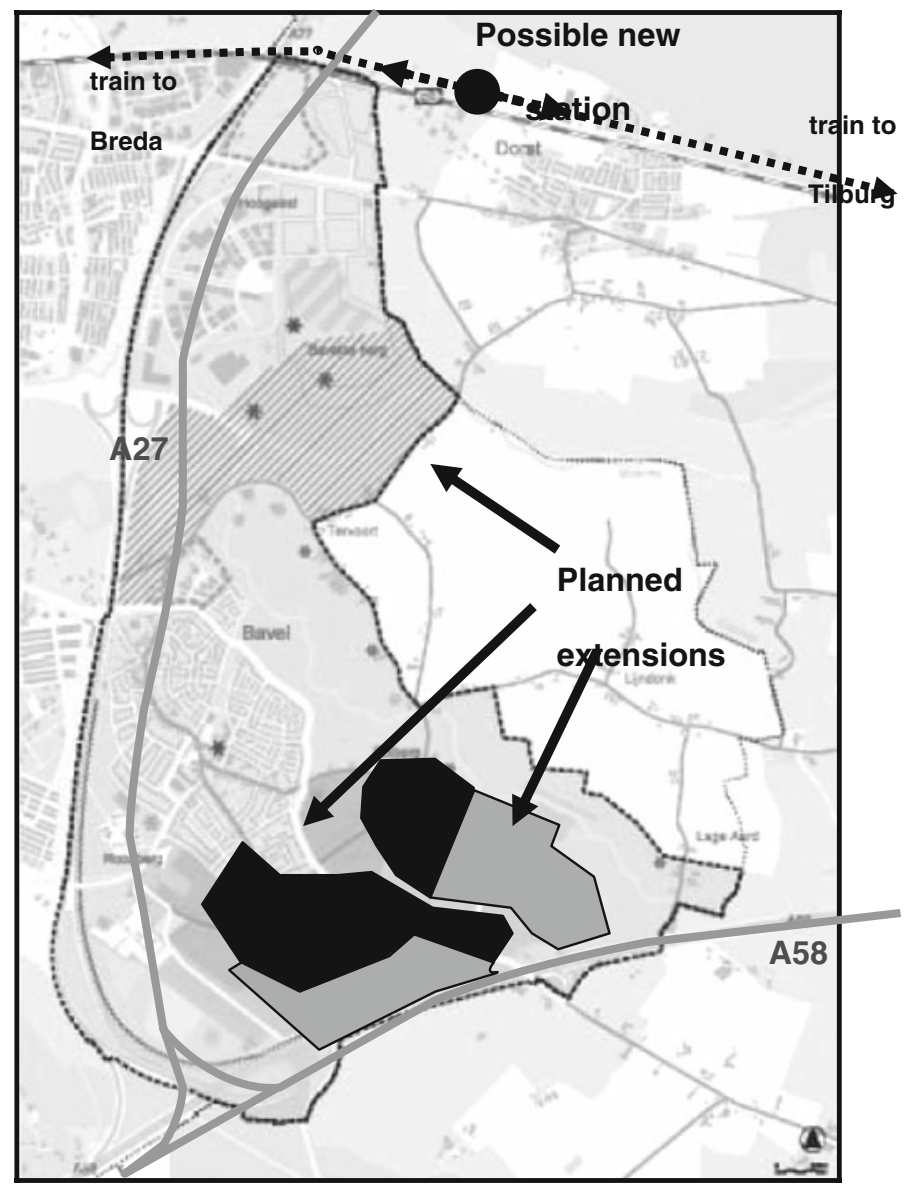

Fig. 4 Spatial structural plan of Breda and the new railway station; black for housing, grey for working functions and shaded for a leisure centre (adapted from Gemeente Breda 2005, p. 4)

municipality of Oosterhout (potentially affected by the proposed railway station) deliberated how to integrate the train station with land use proposals that had recently been approved by the municipality. As a key stakeholder who determines the feasibility of the station, two strategic planners of the Dutch Railways facilitated the process with their Circalex model (calculating potential new train users based on land uses around the station), along with the transport consultant Goudappel Coffeng (who calculated the cumulative opportunity measures [accessibility] for different travel modes).

In the first step, the framing of the planning problem (see Fig. 3), the participants decided to split the group because they realized there were two (related but distinct) planning issues which needed specific attention: (1) how to optimize the user base of the railway station by maximizing functions in its catchment area and (2) how to integrate the recent land use proposals with the public transport system. In the second step, determining the appropriate planning process, both teams chose to work according to the three step design approach used in Amsterdam (diverging, converging, selecting). Again, they emphasized that the preferred outcome were shared LUT insights ('no regret' or 'robust' 
strategies and LUT interdependencies) and not a LUT plan. In the third step, the teams chose different supporting information. The railway station team decided to base their design on the Circalex model; considering development opportunities near the station, its support for train use was optimized by adding jobs and housing. The other team assessed and optimized the public transport strategies by using maps of the current networks and comparing them with sophisticated accessibility maps (which show the most accessible locations for car, transit, slow modes and combinations based on a cumulative opportunity measure). These maps illustrated the potential for a specific strategy to effectively change the accessibility of an area from car oriented to public transport oriented. Thanks to the preparatory interviews, these three steps could all be performed in one morning session. The fourth step, using the information to develop strategies, took place in the second and third session, during which the group also developed a list of 'no regret' strategies and LUT interdependencies (the final step). These steps follow the ordering presented in Fig. 3.

Outcome: integrated strategies

Examples of 'no regret' LUT strategies in Breda were:

- Even if the new station is unlikely to be feasible at present, future spatial plans should always keep the option to develop high-end offices or housing near the proposed station open, and thus realize emerging opportunities. For example, if the region decides to invest in a regional rail network, the possibility of locating high density developments at the station would be very beneficial.

- Basic public transport (a regular bus travelling to the city centre every half hour) has to be provided in the new housing and working areas. It would significantly increase the accessibility by public transport, although it would not make Breda-Oost a top public transport location. In the present context, the latter is not a realistic option (an important point to be communicated to the municipal councilpersons).

- Do not develop a Bus Rapid Transit system only for this area, as there are insufficient numbers of inhabitants and jobs to support it. Despite the politicians' drive to develop Breda-Oost into a top public transport location, the strategies demonstrate that it would be an expensive investment yielding weak results. Such analysis increases the politicians' awareness of costs and benefits.

- As the new areas in Breda-Oost will not become a top public transport location it is necessary to also plan for car accessibility. If this is neglected, the area will probably face problems in the housing market and in the realm of mobility.

- Developing mixed living and working areas would increase employment opportunities in the close vicinity of housing and would encourage a more balanced use of (public transport) infrastructure. The accessibility maps showed that accessibility is not only improved by mobility but also by such land use measures.

Besides these strategies, the group learned about LUT interdependencies:

- If all the spatial opportunities in the vicinity are filled, then the railway station is feasible (for construction and exploitation by Dutch Railways); however, given the rural character of its surroundings this is hardly realistic.

- If there is no clarity about the exact spatial program, then the station should not be developed. All of the available land use potential needs to be developed in order for the station to be viable; therefore, uncertainty about the surrounding developments is not acceptable; 
- If public transport is going to play a big role in this area, then it should focus on improving access to shopping activities in the city centre (in combination with a 'Park and Ride' near the leisure centre and pricing incentives for inner city parking). The additional volume of users would make an enhanced bus service to Breda-Oost feasible.

- If the leisure centre focuses on big single national events and on young people (rock concerts) then the station can play an important role. If the focus is on regional/local events, on mixed public and on continuous visitors (e.g., skiing hall) then the train will play only a marginal role.

The participants acknowledged that they gained new insights about LUT interdependencies and recognized that such an integrated process "should have been included in the development process of the land use plans." They also agreed that similar processes "should be done in early stages of future projects." Especially the exchange of the previously one-directional land use or transport views of an area was seen as an added value (i.e., the exchange of tacit knowledge). Similar to the Amsterdam case, the initial discussion and agreement on what was relevant explicit knowledge for the issues at hand proved a starting point for a structured substantive exchange with more depth than usual. In the words of one transport planner: "although it makes the process more complex at the start, it will show its advantages in the end." On an individual level, the participants stated that they learned more about the useful applications of explicit information in providing support to LUT projects.

Mechanism: knowledge generation

Below, we will again review the four elements of the SECI spiral and analyze how they supported the process of LUT strategy development.

\section{Socialization}

Even though for the specific case of Breda-Oost it happened too late in the planning process; socialization did produce valuable insights for future projects. The interaction with planners of the Dutch Railways was of particular significance, as the planners could better understand the company's position regarding the financing of new railway stations. By explaining and openly discussing their reasoning, the Dutch Railways planners could link up with the knowledge and planning processes of the land use and transport planners and vice versa.

In the fourth step, designing strategies, the planners discussed the balance between the ideal and the feasible development around the station. The land use planners emphasized to the transport planners their concerns regarding nature preservation in the area.

\section{Externalization}

Selecting and discussing an appropriate process and indicators (step two and three) were a crucial part of the first session. Due to a lack of modelling capacity in Breda, primarily the railway planners and the consultant provided the information; this involved a greater leap for all planners as they had no significant prior experience with this type of information. For instance, the Circalex model was not seen as useful at the start; however, while using information later to develop strategies (step four), the model was seen as more appropriate 
and had a central place in designing the interventions (a 'learning by doing' mechanism). Again, the evident difficulty of bridging tacit and explicit knowledge surfaced in the perception of the accessibility indicators as too complicated and insufficiently detailed. It seemed that the absence of the PSS developer (who did not attend all workshops) was an important barrier hampering the effective use of the information. In a following workshop, this was overcome through a dialogue between planners and the PSS developer in between workshops, which clarified the information demand.

\section{Combination}

Clear examples of combinations are found in the maps showing the current plans and possible intervention effects. The municipality provided the former, while the latter came from the Dutch Railways (in the station team) and the consultant (in the public transport team). As a result, the inconsistencies and (missed) integration opportunities were clearly identified.

\section{Internalization}

As in Amsterdam, the importance of modeller participation during the entire process was crucial. In the fifth step (during the third session), with the consultant absent, there was little internalization of the results and the public transport group was unable to develop a shared list of strategies. A fourth session was prepared, where the consultant could present and clarify the assumptions and reasoning behind the accessibility maps. Only then was the group able to compose a full and shared list of strategies.

\section{Conclusions}

The paper started by introducing the difficulties of integrated LUT strategy development and the low implementation rates of associated planning support tools. We presented knowledge (specifically through the process of knowledge generation) as an important mechanism which can bridge the substantive differences between land use planners and transport planners. The cases of Amsterdam and Breda analyzed if and how knowledge generation (through socialization, externalization, combination and internalization) can support integrated LUT strategy-making. Based on the results, we can conclude that (1) integrated LUT strategy-making is still not commonplace practice in the Netherlands; (2) land use planners and transport planners have different sets of tacit and explicit knowledge, this gap hampers providing support with explicit knowledge; (3) the concept of knowledge generation and its application in a step-by-step iterative planning support development process offers useful guidelines for improving the link between tacit and explicit knowledge through a process of knowledge interactions; and (4) through such a process planners can develop shared knowledge and ultimately integrated strategies.

We set out in this paper to explore the functioning of the mechanisms behind the intervention (knowledge generation) and its outcomes (shared LUT strategies), grounded in a specific context (land use and transport planners participating in strategy-making processes at the local/regional scale in the Netherlands). Based on a literature study and on observations, questionnaires and interviews of two explorative cases, we can conclude that: 
- From knowledge management literature, it can be extracted that socialization is an important process which creates shared LUT knowledge, because it increases insight in the working methods and the underlying assumptions in both domains.

- From knowledge management literature, we learn that for socialization to be constructive, both processes of externalization and internalization are crucial. The planners are stimulated to express their tacit knowledge in a shared explicit language of indicators and information. The socialization process is steered beyond mere discussion into designing and testing of alternatives.

- Our cases confirmed these general findings. In addition, they emphasized that both the planning problem and the supporting information (content of the PSS) have to be discussed and selected in open dialogue between planners and PSS developers. The result is a contextualized PSS connected to the planner's specific needs and sets of tacit knowledge. It also takes into account what PSS developers can deliver in practice.

- The cases also indicated that PSS developers (modellers) need to be present throughout the process (from problem definition to strategy selection) to support externalization and internalization of the explicit LUT knowledge provided by their tools.

- Finally, the cases seem to show that for such an integrated strategy-making process to be useful for the planners, it has to be set up as an environment in which they can learn about important LUT relations. The absence of an immediate link to the formal political decision process seems part of this (for instance, when at one point in Breda an attempt was made to capitalize on the unfolding dialogue with the railways and elicit a deal the free exchange of knowledge abruptly stopped). The goal is not to develop a final LUT plan or vision, but rather to develop shared insights (in robust measures [no regret] and tradeoffs [LUT interdependencies]). This common knowledge can be used in future situations and can be communicated to politicians and other actors.

\section{Reflection and discussion}

This study shows that socialization of knowledge might be an important element in integrated LUT strategy-making. However, simply placing the practitioners in one room will not produce the desired results; communication alone is not enough. To bridge the substantive barrier (linking their different sorts of tacit knowledge), they have to be systematically supported with relevant explicit LUT knowledge through processes of externalization and internalization. On the one hand, these processes provide structure and content for debate, enabling learning effects; while on the other hand, they trigger participants to share tacit knowledge, develop new combinations of explicit knowledge and internalize a common language. When we compare this with other research about the caveats of collaborative planning (Innes and Gruber 2005) we see that in our cases there was more distance between the meetings and actual decision making. Also, the meetings comprised mainly what Innes and Gruber call 'staff'. This distance and composition allowed for more focus on learning instead of negotiation, although this focus had to be made clear from the beginning, and re-established on occasions. Innes and Gruber see conflicting planning styles as a major reason for the failure of collaboration. In our cases the styles of planners differ somewhat, but they all seem more or less to employ a technical/bureaucratic style. This is of course related to the closed composition with only limited involvement of external stakeholders. The lack of conflict also has to do with the history of cooperation among the planners. Although in Breda there were two 
municipalities involved, the focus on a relatively abstract level of strategy making prevented a focus on conflict.

The two cases seem to show that full benefits of acquiring new shared knowledge can be obtained only by going through the entire knowledge generation cycle. The research methodology of practice oriented experiments does not allow for a control group; however, the examples of 'normal' daily planning practices where at best just socialization takes place (little or no systematic externalization, combination and internalization of knowledge) show that these processes mostly do not generate new LUT knowledge or strategies. This point was also confirmed by the participants. The same argument could be made for processes of simple combination; i.e., scientists or PSS developers building new models and instruments based on combinations of scientific insight and without interaction with planners' tacit knowledge (and thus no internalization).

Although the concept of knowledge generation provides a useful analytic framework for analyzing new learning by artificially dividing the process in categories, in the real world the four modes of knowledge conversion overlap and dynamic shortcuts occur (see also Gourlay 2003). In both cases there were moments where several (or even all) four steps were taken at the same time (simultaneous internalization and externalization during design steps). Also, some steps occurred more often than others and in different sequences. Thus, although all steps are important, the framework should be applied with some flexibility.

A social learning process seems important for successful LUT strategy-making (or other strategy-making which concerns separate planning and/or knowledge domains). The planners face complex planning environments in which they are only one of many actors who try to shape the future of a city or region. They are involved in planning processes, marked by great uncertainties and the unpredictability of shifting conditions on the ground. For them, it seems much more useful to develop better, and more shared knowledge about crucial relationships than to develop a final vision or plan. Also, if the participants realize that it is a learning process, they are more open to sharing their tacit knowledge and discussing their assumptions. In Breda, one participant explicitly stated that he only joined the process because it did not aim at negotiation, which would have hampered learning. At least for the initial, strategy identification phases of planning processes, the prevalence of a learning mode seems essential.

The research described here, is based on observations, (qualitative) questionnaires, and interviews. However, more detailed analysis of the exact nature of what tacit knowledge was exchanged between the participants and how this impacted on the practical outcomes is still underway. This has to do with the different time scales of different kinds of outcomes. Direct learning effects can be analysed on the spot (accurately measuring them is a whole different matter), but the translation of these learning effects in concrete plans or other follow up (ex. more regular interaction between land use and transport planners in the organization) can take some time. Analysis of such outcomes is planned in the near future.

An interesting topic for further research would be to explore if such learning processes (four knowledge conversion steps) could also work with more actors and/or in less structured environments. For analytic clarity, we focussed on processes almost exclusively involving professional planners, but in practice strategy-making often involves cooperation with different stakeholders and citizens (especially so in North America, see Zapatha and Hopkins 2007). The potential for such structured learning seems particularly high in these types of open processes, due to the big gaps between tacit and explicit knowledge.

This idea of strategy-making as social learning also has impact on the development of relevant planning support. As the cases show, in the early phases of planning, the selection and contextualization of a common language is a crucial part of knowledge generation; 
PSS which are developed on the basis of generic views of planning and models are therefore difficult to apply. For a PSS to be relevant, it seems that the developers (modellers) have be open to engage in the learning process as well and be open for implementing changes in their instruments (even if this implies sacrificing some scientific rigor for the benefit of practical relevance). In the world of land use and transport planning, this would imply a different way of using transport models (more as communicative instead of predictive devices), in turn recognizing their limitations and subjectivity (as also argued by Timms 2008). This paper focused on developing support for planners from two domains; however, more research is needed specifically on the position of the PSS developer (modeller) in this process.

Acknowledgments We would like to thank three anonymous referees for their stimulating comments to a previous version of this paper. The research discussed in this article is part of the research project "Designing Sustainable Accessibility" (DESSUS), which is made possible with support of Transumo. Transumo (TRANsition SUstainable MObility) is a Dutch platform for companies, governments and knowledge institutes that cooperate in the development of knowledge with regard to sustainable mobility.

Open Access This article is distributed under the terms of the Creative Commons Attribution Noncommercial License which permits any noncommercial use, distribution, and reproduction in any medium, provided the original author(s) and source are credited.

\section{References}

Banister, D.: Transport planning. Spon Press, New York (2002)

Banister, D.: Unsustainable transport: city transport in the new century. Routledge, London (2005)

Brabantstad: Verkenning OV-netwerk Brabantstad: Samen investeren. Brabantstad, Den Bosch (2003)

Cabinet Office: Wiring it up. Whitehall's management of cross-cutting policies and services. A performance and innovation unit report. The Stationery Office, London (2000)

Cervero, R.: The transit metropolis: a global inquiry. Island Press, Washington, DC (1998)

Couclelis, H.: Where has the future gone? Rethinking the role of integrated land-use models in spatial planning. Environ. Plan. A 37, 1353-1371 (2005)

Denyer, D., Tranfield, D., Van Aken, J.E.: Developing design propositions through research synthesis. Organ. Stud. 29(03), 393-413 (2008)

Ehrmann, J., Stinson, B.: Joint fact-finding and the use of technical experts. In: Susskind, L., McKearnan, S., Thomas-Larmer, J. (eds.) The consensus building handbook. Sage publications, Thousand Oaks (1999)

Emberger, G., Ibesich, N., Pfaffenbichler, P.: Can decision making processes benefit from a user friendly land use and transport interaction model?, 8th International Conference on Design \& Decision Support Systems in Architecture and Urban Planning, Eindhoven (The Netherlands) (2006)

Friedmann, J.: Retracking America, a theory of transactive planning. Anchor Press/Doubleday, Garden City, NY (1973)

Geertman, S.: Potentials for planning support: a planning-conceptual approach. Environ. Plan. B: Plan. Des 33(6), 863-880 (2006)

Gemeente Breda: Bavel, Beek en Berg: Voorontwerp Structuurplan Breda-Oost. Breda (2005)

Gibbons, M., Limoges, C., Nowotny, H., Schwartzman, S., Scott, P., Trow, P.: The new production of knowledge: the dynamics of science and research in contemporary societies. Sage, London (1994)

Gourlay, S.: The SECI model of knowledge creation: some empirical shortcomings. In: McGrath, F. and Remenyi D. (ed.) Fourth European conference on knowledge management, Oxford, 18-19 September 2003, pp. 377-385

Gourlay, S.: Conceptualizing knowledge creation: a critique of Nonaka's Theory. J. Manag. Stud. 43(7), 1415-1436 (2006)

Healey, P.: Urban complexity and spatial strategies: towards a relational planning for our times. Routledge, London (2007)

Hull, A., Tricker, R.: Findings of the 'phase 1' Survey on the barriers to the delivery of sustainable transport solutions. UWE, Bristol (2006)

Innes, J.E.: Information in communicative planning. JAPA 64(1), 52-63 (1998) 
Innes, J.E., Gruber, J.: Planning styles in conflict: the metropolitan transportation commission. J. Am. Plan. Assoc. 71((2), 177-188 (2005)

Jones, P., Lucas, K.: Option generation: literature review. UCL, London (2005)

Khakee, A., Barbanente, A., Borri, D.: Expert and experiential knowledge in planning. J. Oper. Res. Soc. 51(7), 776-788 (2000)

Klosterman, R.E.: Deliberating about the future. In: Hopkins, L.D., Zapata, M.A. (eds.) Engaging the future: forecasts, scenarios, plans and projects, pp. 199-219. Lincoln Institute of land policy, Cambridge (2007)

Meyer, M.D., Miller, E.J.: Urban transportation planning: a decision-oriented approach. McGraw-Hill, New York (2001)

Mintzberg, H., Waters, J.A.: Of strategies, deliberate and emergent. Strateg. Manag. J. 6, 257-272 (1985)

Nonaka, I., Konno, N.: The concept of 'Ba': Building a foundation for knowledge creation. California Manag. Rev. 40(3), 40-54 (1998)

Nonaka, I., Takeuchi, H.: The knowledge-creating company: how Japanese companies create the dynamics of innovation. Oxford University Press, New York (1995)

Nonaka, I., von Krogh, G., Voelpel, S.: Organizational knowledge creation theory: evolutionary paths and future advances. Organ. Stud. 27(8), 1179-1208 (2006)

Noordvleugel.: Metropoolregio Amsterdam: Ontwikkelingsbeeld Noordvleugel 2040. Amsterdam (2008)

Nowotny, H., Scott, P., Gibbons, M.: Re-thinking science: knowledge and the public in an age of uncertainty. Polity, Cambridge (2001)

Pawson, R., Tilley, N.: Realistic evaluation. Sage, London (1997)

Polanyi, M.: The tacit dimension. Doubleday, New York (1967)

Scharmer, C.O., Kaufer, K.: Universities as the birthplace for the entrepreneurial human being. reflections. The SOL J. Knowl. Learn. Chang. (2000)

Schön, D.: The reflective practitioner: how professionals think in action. Temple Smith, London (1983)

Schön, D., Rein, M.: Frame reflection: toward the resolution of intractable policy controversies. Basic Books, New York (1994)

Simon, H.A.: Strategy and organizational evolution. Strateg. Manag. J. 14, 131-142 (1993)

Stead, D., Geerlings, H., Meijers, E.: Policy integration in practice. The integration of land use planning, transport and environmental policy-making in Denmark, England and Germany. Delft University Press, Delft (2004)

Te Brömmelstroet, M.C.G.: Equip the warrior instead of manning the equipment: state of practice of land use and transport planning support in the Netherlands. J. Transp. Land Use, forthcoming (2009)

Te Brömmelstroet, M.C.G., Bertolini, L.: Developing land use and transport PSS: meaningful information through a dialogue between modelers and planners. Transp. Policy 15(4), 251-259 (2008)

Tennøy, A.: Why we fail to reduce urban road traffic volumes: does it matter how planners frame the problem? Transport Policy, forthcoming (2009)

Timms, P.: Transport models, philosophy and language. Transportation 35(3), 395-410 (2008)

TRB: A new vision for mobility: guidance to foster collaborative multimodal decision making. Transportation Research Board, Washington DC (2004)

Tsoukas, H.: Do we really understand tacit knowledge? In: Easterby-Smith, M., Lyles, M.A. (eds.) Organizational learning and knowledge management, pp. 410-425. Blackwell Publishing, Oxford (2003)

Uran, O., Janssen, R.: Why are spatial decision support systems not used? Some experiences from the Netherlands. Comput. Environ. Urban. Syst. 27, 511-526 (2003)

Van der Bijl, R., Witsen, P.P.: Probleemoplossers versus toekomstdenkers. Blauwe Kamer 4, 28 -36 (2000)

Vennix, J.A.M.: Group model building: facilitating team learning using system dynamics. Wiley, Chicester (1996)

Vonk, G., Geertman, S., Schot, P.: Bottlenecks blocking widespread usage of planning support systems. Environ. Plan. A 37, 909-924 (2005)

Wachs, M.: When planners lie with numbers. J. Am. Plan. Assoc. 55, 476-479 (1985)

Waddell, P.: UrbanSim: Modeling Urban Development for Land Use, Transportation and Environmental Planning. J. Am. Plan. Assoc. 68(3), 297-314 (2002)

Wegener, M.: Overview of land-use and transport models. In: Henscher, D.A., Button, K. (eds.) Transport geography and spatial systems. Pergamon/Elsevier Science, Kidlington (UK) (2005)

Willson, R.: Assessing communicative rationality as a transportation planning paradigm. Transportation 28, $1-31(2001)$

Wilson, A.G.: Land-use/transport interaction models, past and future. J. Transp. Econ. 32(1), 3-26 (1998)

Zapatha, M.A., Hopkins, L.D.: Engaging the future: forecasts, scenarios, plans and projects. Lincoln Institute of Land Policy, Cambridge, Massachusetts (2007) 


\section{Author Biographies}

Marco Te Brömmelstroet is a $\mathrm{PhD}$ Candidate at the Amsterdam Institute for Metropolitan and International Development Studies (AMIDSt) of the University of Amsterdam. His main academic interests are the implementation gap of Planning Support Systems, the use of transportation models in decision making and the integration of transport and land use strategy making.

Luca Bertolini is Professor of Urban and Regional Planning at the University of Amsterdam. His main interests are the integration of transport and land use planning, methods for supporting the option-generation phase of the planning process, concepts for coping with uncertainty in planning, and ways of enhancing theory-practice interaction. 